\title{
ALTERAÇÕES DO LIPIDOGRAMA APÓS ESPLENECTOMIA TOTAL, ESPLENECTOMIA SUBTOTAL E AUTO-IMPLANTE ESPLÊNICO EM RATAS
}

Lipidogram alterations after total splenectomy, subtotal splenectomy and splenic auto-implants in rats

\author{
Andy Petroianu, Denny Fabrício Magalhães Veloso, Luiz Ronaldo Alberti
}

\begin{abstract}
RESUMO
Objetivo: Apesar de serem bem estabelecidas as alterações esplênicas nas dislipidemias, como a doença de Gaucher, ainda não se estudou adequadamente a relação do baço com o metabolismo lipídico. Visando contribuir para preencher esse hiato, a presente investigação avaliou experimentalmente o lipidograma na presença do baço, em asplenia e após operações conservadoras desse órgão. Métodos: Foram utilizadas 50 ratas Wistar de peso e idades semelhantes distribuídas em quatro grupos: Grupo 1 - controle, com baço íntegro; Grupo 2 laparotomia e laparorrafia, Grupo 3 - esplenectomia total; Grupo 4 - esplenectomia subtotal e Grupo 5 - esplenectomia total complementada por implantes de tecido esplênico autógeno. Após quatro meses, foram dosados os níveis séricos de triglicérides, colesterol total e suas frações VLDL, LDL, HDL. Os resultados dos quatro grupos foram comparados entre si pela análise de variância, seguido pelo teste de Tukey-Kramer, com significância para $\mathrm{p}<0,05$. Resultados: Não houve diferença entre os grupos 1, 2, 3 e 4. Nos animais submetidos a esplenectomia total, as concentrações de colesterol total $(p=0,0151)$ e de sua fração LDL $(p<0,0001)$ foram maiores, enquanto a fração HDL foi menor $(p=0,0026)$ do que as encontradas nos demais grupos. Não houve diferença entre grupos com relação aos triglicérides ( $p$ $=0,1571)$ e VLDL $(\mathrm{p}=0,2527)$. Conclusões: É provável que o baço desempenhe um papel de destaque no metabolismo lipídico de ratas e que a esplenectomia total se relacione com alterações no controle do colesterol. É possível que a preservação de tecido esplênico previna tais distúrbios metabólicos.
\end{abstract}

Descritores: Baço, Esplenectomia, Transplante, Colesterol, Triglicérides.

Instituição:

Departamento de Cirurgia, Faculdade de Medicina - Universidade Federal de Minas Gerais

\section{Correspondência:}

Prof. Andy Petroianu

Av. Afonso Pena, 1626 - apto. 1901 - Belo Horizonte / MG - CEP: 30130-005 - Brasil

Tel./Fax: (31) 32747744

E-mail: petroian@medicina.ufmg.br

Recebido em: 01.10.2008

\section{INTRODUÇÃO}

As funções do baço fazem parte do metabolismo orgânico e distúrbios desse órgão relacionam-se com diferentes doenças. ${ }^{1-}$ ${ }^{10}$ Afecções nos depósitos lisossômicos são consideradas as alterações metabólicas mais freqüentemente associadas a um defeito enzimático envolvendo o baço. Na doença de Gaucher, por exemplo, o acúmulo de glicocerebrosídeos nos lisossomos das células do sistema reticuloendotelial, leva à formação de células carregadas de lípides conhecidas como células de Gaucher. Esse acúmulo de glicocerebrosídeos nos macrófagos do baço e nas células de Kupffer do fígado provoca aumento desses órgãos. Além disso, outras esfingoliposes, tais como a doença de NiemannPick, as gangliosidases e a doença de Faber também apresentam manifestações esplênicas..$^{10} \mathrm{O}$ baço participa do metabolismo de todos os metais, dos albuminóides e da bilirrubina indireta, a partir das hemácias fagocitadas.11,12

Pacientes portadores de doenças mieloproliferativas (policitemia vera e mielofibrose) acompanhadas de metaplasia mielóide e de hiperesplenismo cursam com esplenomegalia e apresentam diminuição dos valores de colesterol total, HDL, apolipoproteína B e apolipoproteína A-1. Nessas doenças, a esplenectomia normaliza os valores dessas substâncias., ${ }^{2,713}$

Há uma evidente e comprovada relação entre dislipidemia e doenças vasculares, em especial aterosclerose, que é responsável 
por elevada morbimortalidade na população geral. Fatouros et al (1995) observaram que pessoas esplenectomizadas por trauma apresentavam maior incidência de coronariopatias por aterosclerose decorrente, provavelmente de distúrbios lipídicos. ${ }^{2}$ As alterações no metabolismo lipídico em decorrência de esplenectomia por trauma poderiam eventualmente explicar a alta incidência de infarto agudo do miocárdio relatada em veteranos da Segunda Guerra Mundial ${ }^{14}$.

Algumas pesquisas experimentais relacionam a influência do baço no metabolismo das gorduras. King, em 1914, verificou aumento do colesterol em cães, após remoção esplênica. ${ }^{15}$ Asai et al ${ }^{4}$ observaram que coelhos que se alimentavam de produtos com altos níveis de colesterol tinham aumento de colesterol, triglicérides, fosfolípides, e baixos níveis de HDL após a retirada do baço. Esse fato foi também relatado em ratos com alimentação enriquecida com colesterol. ${ }^{2}$

Apesar da ampla documentação na literatura sobre as dislipidemias, ainda são muito poucos e controversos os trabalhos correlacionando o baço e o efeito das operações esplênicas conservadoras no metabolismo lipídico. Diante desse hiato, o presente trabalho avaliou experimentalmente a influência do baço e de diferentes operações realizadas sobre ele, assim como do auto-implante esplênico no lipidograma.

\section{MÉTODOS}

O presente trabalho foi realizado de acordo com as recomendações das Normas Internacionais de Proteção aos Animais e do Código Brasileiro de Experimentação Animal (1988) e foi aprovado pela Comissão de Ética do Departamento de Cirurgia da Faculdade de Medicina da Universidade Federal de Minas Gerais (UFMG) ${ }^{16,17}$

Foram utilizadas 40 ratas Wistar com peso médio de $133 \pm$ 19 gramas, procedentes do Biotério do Instituto de Ciências Biológicas da UFMG e mantidos no Biotério da Faculdade de Medicina da UFMG.

Os animais foram alocados em gaiolas apropriadas, com até cinco animais por gaiola, à temperatura ambiente de $25^{\circ} \mathrm{C}$ e iluminação diária natural. Eles receberam água e ração balanceada padrão para ratos à vontade. Antes do experimento, as ratas foram submetidas a exame para descartar possíveis afecções, durante o período de adaptação de 15 dias. Os animais foram distribuídos aleatoriamente nos seguintes grupos:

Grupo $1(\mathrm{n}=10)$ - Controle: não foram submetidos a intervenção cirúrgica.

Grupo 2 ( $\mathrm{n}=10)$ - Esplenectomia total: o estômago foi tracionado para fora da cavidade abdominal, expondo o baço. Em seguida, foram realizadas três ligaduras do pedículo vascular esplênico com fio de categute cromado 5-0 e retirada completa do órgão.

Grupo $3(\mathrm{n}=10)$ - Esplenectomia subtotal: ligadura vascular do baço com fio de categute cromado 5-0, deixando apenas o pólo superior suprido pelos vasos esplenogástricos, secção do baço entre as partes isquêmica e irrigada. Sutura contínua da superfície cruenta do pólo esplênico superior com fio de categute cromado 5-0.

Grupo $4(\mathrm{n}=10)$ - Esplenectomia total complementada por implante de tecido esplênico autógeno no omento maior. Após a retirada do baço, seguindo as etapas descritas no Grupo 2, fatiou-se o órgão em cinco segmentos que foram suturados sobre o omento maior, com fio de categute cromado 5-0.
Todos os procedimentos foram realizados nas dependências do Laboratório de Cirurgia Experimental do Departamento de Cirurgia da Faculdade de Medicina da UFMG, obedecendo às normas técnicas de assepsia e anti-sepsia.Todos os procedimentos operatórios foram conduzidos sob anestesia geral com éter etílico e através de laparotomia mediana, de aproximadamente $4 \mathrm{~cm}$, iniciada 0,5 cm abaixo do apêndice xifóide, no sentido crânio-caudal. A cavidade abdominal das ratas foi fechada em dois planos de sutura contínua (no primeiro, o peritônio e plano músculo aponeurótico e, no segundo, a pele), utilizando fio de algodão 5-0.

As ratas foram acompanhadas diariamente durante 120 dias. Decorrido esse prazo, elas foram anestesiadas com éter etílico e submetidas a laparotomia mediana. Identificou-se a veia cava caudal, que foi puncionada sob sistema de coleta a vácuo, no qual foram coletados $5 \mathrm{ml}$ de sangue em tubos com gel e revestidos com papel alumínio para proteção da luz, que foram imediatamente enviados para análise laboratorial. Após centrifugação a 2000 rpm por cinco minutos do plasma separado, dosou-se as concentrações de triglicérides, colesterol total e HDL pelo método colorimétrico enzimático. As concentrações das frações do colesterol VLDL e LDL foram calculadas pela fórmula de Friedwald. Em seguida, os animais foram mortos com dose inalatória letal de éter.

Os valores de colesterol total e suas frações e de triglicérides foram avaliados nos diferentes grupos pelo teste de Normalidade de Kolmogorov-Smirnov (KS) para testar a distribuição gaussiana dos dados e, em seguida, pelo teste de Bartlett para testar as variâncias. Caso os dados apresentassem distribuição gaussiana e mesma variância, realizava-se análise de variância (ANOVA) seguida pelo teste de Tukey-Kramer de comparação múltipla. Os valores eram considerados significativos quando $\mathrm{p}<0,05$.

\section{RESULTADOS}

No Grupo 2, dos animais esplenectomizados, houve três mortes na primeira semana pós-operatória sem causa aparente ao exame macroscópico da cavidade abdominal. Esses animais foram substituídos, para manter a uniformidade do número de animais em cada grupo. Não foram verificadas adversidades nos outros grupos. Os animais recuperaram-se rapidamente do procedimento cirúrgico.

Todas as dosagens de colesterol total apresentaram valores com distribuição dentro da curva normal $(p>0,10)$ (distância KS de 0,1572 para o Grupo 1, KS de 0,3355 para o Grupo 2, KS de 0,1396 para o Grupo 3 e KS de 0,1949 para o Grupo 4). As variâncias não foram diferentes $(p=0,9325$ pelo teste de Bartlett). Os animais submetidos à esplenectomia total (Grupo 2) apresentaram maiores concentrações de colesterol total ( $p$ $=0,0093$ ANOVA) em relação aos demais grupos. Não houve diferença entre os outros grupos. (Tabela 1)

As dosagens da fração VLDL do colesterol apresentaram valores de distribuição dentro da curva normal (p > 0,10) (distância KS de 0,2140 para o Grupo 1, KS de 0,2271 para o Grupo 2, KS de 0,1822 para o Grupo 3 e KS de 0,2800 para o Grupo 4). As variâncias não foram diferentes $(p=0,4665$ pelo teste de Bartlett). Não houve diferença com significância estatística entre os grupos $(p=0,2030$, ANOVA). (Tabela 1).

As dosagens da fração LDL do colesterol apresentaram valores com distribuição dentro da curva normal $(p>0,10)$ (distância 
Tabela 1. Valores do colesterol total e suas frações, e dos triglicérides (média \pm desvio padrão da média) nos animais do grupo controle e dos submetidos a operações sobre o baço.

\begin{tabular}{cccccc}
\hline Grupo & \multicolumn{4}{c}{ Colesterol } & Triglicérides \\
\hline & HDL *1 & VLDL & LDL *2 & Total *3 & \\
\hline 1 & $51,1 \pm 12,8$ & $10,1 \pm 2,9$ & $16,6 \pm 9,0$ & $77,9 \pm 8,4$ & $50,3 \pm 14,0$ \\
2 & $37,6 \pm 11,0$ & $13,9 \pm 4,5$ & $38,3 \pm 13,7$ & $89,7 \pm 10,7$ & $68,9 \pm 21,8$ \\
3 & $55,1 \pm 11,8$ & $13,4 \pm 3,8$ & $7,8 \pm 9,0$ & $74,4 \pm 9,2$ & $67,7 \pm 18,9$ \\
4 & $50,4 \pm 14,7$ & $12,4 \pm 5,0$ & $12,0 \pm 11,7$ & $74,6 \pm 9,1$ & $62,4 \pm 25,3$ \\
\hline
\end{tabular}

Grupo 1: Controle

Grupo 2: Esplenectomia total

Grupo 3: Esplenectomia subtotal

Grupo 4: Esplenectomia total + auto-implante esplênico

*1: $\mathbf{p}=\mathbf{0 , 0 5}$ (Grupo 2 em relação aos demais grupos)

*2: $\mathbf{p}<\mathbf{0 , 0 0 0 1}$ (Grupo $2 \mathrm{em}$ relação aos demais grupos)

*3: $\boldsymbol{p}=0093$ (Grupo 2 em relação aos demais grupos

KS de 0,2142 para o Grupo 1, KS de 0,2065 para o Grupo 2, KS de 0,2912 para o Grupo 3 e KS de 0,1967 para o Grupo 4). As variâncias não foram diferentes $(\mathrm{p}=0,6111$, pelo teste de Bartlett). Os animais submetidos à esplenectomia total (Grupo 2) apresentaram maiores concentrações de colesterol LDL (p $<0,0001$ ANOVA) em relação aos demais grupos. Não houve diferença entre os outros grupos. (Tabela 1)

As dosagens da fração HDL do colesterol apresentaram valores com distribuição dentro da curva normal ( $p$ > 0,10) (distância KS de 0,1900 para o Grupo 1, KS de 0,3416 para o Grupo 2, KS de 0,2034 para o Grupo 3 e KS de 0,1690 para o Grupo 4). As variâncias não foram diferentes ( $\mathrm{p}=0,8927$, pelo teste de Bartlett). A fração HDL do grupo submetido a esplenectomia total (Grupo 2) foi menor do que a registrada nos demais grupos ( $\mathrm{p}=0,05$, ANOVA). Não houve diferença significativa entre os outros grupos. (Tabela 1).

As dosagens de triglicérides também apresentaram valores com distribuição dentro da curva normal $(p>0,10)$ (distância KS de 0,2370 para o Grupo 1, KS de 0,2352 para o Grupo 2, KS de 0,1776 para o Grupo 3 e KS de 0,2559 para o Grupo 4). As variâncias não foram diferentes $(\mathrm{p}=0,4310$, pelo teste de Bartlett). Não houve diferença entre os grupos estudados ( $\mathrm{p}=$ 0,1882, ANOVA). (Tabela 1)

\section{DISCUSSÃO}

O baço destaca-se na prática médica em decorrência de suas atribuições, parcialmente já bem conhecidas, como seu papel imunitário, de filtração e hematopoiético. ${ }^{18}$ Além dessas funções, sua participação no controle metabólico vem merecendo uma atenção crescente. ${ }^{1-9}$ Sua importância na fisiopatologia de muitas doenças fez com que se optasse pela preservação desse órgão, reduzindo os índices de sepse e distúrbios hematológicos pósoperatórios. ${ }^{19}$ A esplenectomia total que resultava de muitas indicações no passado vem sendo progressivamente substituída por procedimentos conservadores do baço, como a sutura esplênica, a esplenectomia parcial, a esplenectomia subtotal ou o implante autógeno de tecido esplênico após remoção do baço. ${ }^{18,20-23}$ Mais recentemente, passou a ser bem aceita a abordagem nãooperatória de trauma esplênico, com resultados melhores do que os operatórios. ${ }^{24}$

Existem na literatura, trabalhos clínicos e experimentais avaliando a possível relação entre o baço e o metabolismo lipídico no hiperesplenismo 1-3,6-8 e em presença de asplenia. ${ }^{1,2,5,7,9}$ Gilbert et al (1981) descreveram um decréscimo nos níveis séricos de colesterol total e de suas frações LDL e HDL em pacientes portadores de doenças mieloproliferativas associadas a hiperesplenismo. ${ }^{8}$ Nos períodos de agravamento da doença de base havia redução ainda maior dos níveis de colesterol. Após esplenectomia total ou quando a moléstia era controlada por agentes quimioterápicos ou com irradiação esplênica, ocorreu a reversão da hipocolesterolemia.8 Outros autores também analisaram essa relação em pacientes portadores da doença de Gaucher tipo $1^{6}$ e talassemia maior tipo $\mathrm{B},{ }^{3}$ tendo sido encontrados resultados semelhantes.

Por outro lado, em estudos experimentais a esplenectomia total foi acompanhada de níveis elevados de colesterol e triglicérides. ${ }^{2,4,5}$ Aviram et al (1986) notaram que após esplenectomia para tratar desordens mieloproliferativas, houve elevação da fração LDL do colesterol. ${ }^{7}$

A dislipidemia secundária à esplenectomia total poderia resultar em maior incidência de distúrbios ateroscleróticos. ${ }^{25-29} \mathrm{Na}$ tentativa de estabelecer essa relação, Asai et al (1988) observaram que coelhos submetidos à esplenectomia total e que receberam alimentação rica em colesterol apresentaram após quatro meses placas ateroscleróticas na aorta. ${ }^{5}$

Existem algumas teorias para explicar os possíveis mecanismos implicados na regulação dos lípides plasmáticos pelo baço.,3,5-7 Schmidt et al (1997) compararam o baço a um reservatório lipídico que se eleva em situações de hiperesplenismo. Os macrófagos esplênicos acumulariam grande quantidade de gordura mediante o aumento da fagocitose com conseqüente hipolipidemia ${ }^{1}$. Outra explicação para a redução lipídica seria o efeito imunitário do sistema mononuclear fagocitário contra estruturas encontradas nas lipoproteínas HDL e LDL, resultando em sua depuração plasmática. ${ }^{3,6}$

Com base nessas teorias, após a esplenectomia total o efeito inverso provocaria o aumento dos níveis séricos dos lípides plasmáticos. Entretanto, há necessidade de prosseguir a investigação desse fenômeno, para que seja não só comprovada a veracidade dessas hipóteses, como também se aprofundar em suas explicações.

O presente trabalho também encontrou a elevação do colesterol total e de sua fração LDL. Por outro lado, a fração HDL apresentou concentração menor. Já os níveis de triglicérides e de VLDL foram inalterados, como havia sido descrito por Aviram et al ${ }^{7}$ (1986), contradizendo outros autores. . $2,45^{-1}$

É importante ressaltar que as cirurgias conservadoras do baço mantiveram o lipidograma em seus níveis normais. Portanto, a presença de tecido esplênico mesmo em quantidade menor e até ectópico é capaz de manter as funções do órgão relacionadas à regulação do metabolismo lipídico. Além disso, considerandose a hipótese de que a irrigação sangüínea do omento seria menos propícia que a irrigação própria do baço diminuindo a funcionalidade do órgão, não houve diferenças no lipidograma do Grupo 4 em relação aos grupos 1 e 3. 


\section{CONCLUSÕES}

É provável que o baço desempenhe um papel de destaque no metabolismo lipídico de ratas e que a esplenectomia total se relacione com alterações no controle do colesterol. É possível que a preservação de tecido esplênico previna tais distúrbios metabólicos.

\section{AGRADECIMENTOS}

Os autores agradecem o auxílio da acadêmica de Medicina Renata Figueiredo Rocha pela apresentação deste trabalho e ao CNPq e à FAPEMIG pelos auxílios financeiros.

\section{ABSTRACT}

Purpose: Although the occurrence of spleen alterations in the various forms of dyslipidemia, such as Gaucher's disease has been well established, the relationship between spleen and the lipid metabolism has not been properly studied. In order to contribute to fulfill this gap, the present investigation experimentally assessed the lipidogram of rats in the presence of the spleen, in asplenia, and after conservative spleen surgeries. Methods: Forty female Wistar rats of similar weight and age were divided into 4 groups submitted to the following procedures: Group 1- control, with intact spleen; Group 2 - total splenectomy; Group 3 - subtotal splenectomy, and Group 4total splenectomy complemented with autogenous spleen tissue implants. Four months after the interventions, the serum triglycerides, total cholesterol and fractions (VLDL, LDL, HDL) were determined. Results of the four groups were compared by analysis of variance followed by the Tukey-Kramer test, with level of significance set as $p<0.05$. Results: There were no differences between groups 1,3 and 4. In animals submitted to total splenectomy, the total cholesterol $(\mathrm{p}=0.0093)$ and LDL fraction concentrations $(\mathrm{p}<0.0001)$ were higher, whereas HDL fraction concentrations were lower $(\mathrm{p}=0.05)$ than those detected in the other groups. There was no difference in triglycerides $(p=0.1882)$ or VLDL $(p=0.2030)$ between groups. Conclusions: The spleen probably plays an important role in the lipid metabolism of female rats and total splenectomy may be related to changes in the cholesterol control. It is possible that preservation of the spleen tissue prevents such metabolic disorders.

Keywords: Spleen; Splenectomy; Transplantation; Cholesterol; Triglycerides.

\section{REFERÊNCIAS}

1. Schmidt HH, Wagner S, Manns M. The spleen as a storage pool in lipid metabolism. Am J Gastroenterol. 1997;92:1072-2.

2. Fatouros M, Bourantas K, Bairaktari E, Elisaf M, Tsolas O, Cassioumis D. Role of the spleen in lipid metabolism. Br J Surg. 1995;82:1675-7.

3. Goldfarb AW, Rachmilewitz EA, Eisenberg S. Abnormal low and high density lipoproteins in homozygous beta-thalassaemia. Br J Haematol. 1991;79:481-6.

4. Asai K, Hayashi T, Kuzuya M, Funaki C, Naito M, Kuzuya F. Delayed clearance of beta-very low density lipoprotein after feeding cholesterol to splenectomized rabbits. Artery. 1990;18:32-46.

5. Asai K, Kuzuya M, Naito M, Funaki C, Kuzuya F. Effects of splenectomy on serum lipids and experimental atherosclerosis. Angiology. 1988;39:497-504.

6. Le NA, Gibson JC, Rubinstein A, Grabowski GA, Ginsberg HN. Abnormalities in lipoprotein metabolism in Gaucher type 1 disease. Metabolism. 1988;3:240-5.

7. Aviram M, Brook JG, Tatarsky I, Levy Y, Carter A. Increased low-density lipoprotein levels after splenectomy: a role for the spleen in cholesterol metabolism in myeloproliferative disorders. Am J Med Sci. 1986;291:25-8.

8. Gilbert HS, Ginsberg H, Fargerstrom R, Brown WV. Characterization of hypocholesterolemia in myeloproliferative disease. Relation to disease manifestations and activity. Am J Med. 1981;71:595-602.

9. Bednarik T, Cajthamlova H. Serum proteins after splenectomy in dog, the rabbit and the rat. Physiol Bohemoslov. 1968;17:249-52.

10. Viana MB, Oliveira BM, Oliveira MCLA. O Baço em doenças metabólicas. In: Petroianu A, editor. O Baço. 1 ed. São Paulo: CLR Baliero Editores; 2003, p. 197-205.

11. Constantopoulos A, Najar VA, Wisch JB, Necheles TH, Stolbach LL: Defective phagocytosis due to tuftsin deficiency in splenectomized subjects. Am J Dis Child. 1973;125:663-5.

12. Petroianu A. Estudos experimentais sobre o baço. In: Petroianu A, editor. O Baço. 1 ed. São Paulo: CLR Baliero Editores; 2003, p.414-26.

13. Sugihara T, Yawata Y. Observations on plasma and red cell lipids in hereditary spherocytosis. Clin Chim Acta. 1984;137:227-32.
14. Paulo DNS, Lázaro da Silva A. Lipídeos plasmáticos após esplenectomia total e parcial em cães. Rev Col Bras Cir. 2001;28:264-70.

15. King JH. Studies in the pathology of the spleen. Arch Intern Med. 1914;14:45-67.

16. Cooper JE. Ethics and laboratory animals. Vet Rec. 1985;116:594-5.

17. Petroianu ${ }^{\text {a }}$ Pesquisa experimental. In: Petroianu A, editor. Ética, Moral e Deontologia Médicas. Rio de Janeiro: Guanabara Koogan; 2000, p. 185-90.

18. Petroianu A. Cirurgia do baço. In: Petroianu A, editor. Clínica Cirúrgica. Rio de Janeiro: Revinter; 2001, p.429-42.

19. Morris DH, Bullock FD. The importance of the spleen in resistance to infection. Ann Surg. 1919;70:513-21.

20. Morgenstern L. Evolution of splenic surgery. Contemp Surg. 1986;29:15-8.

21. Morgenstern L. Techniques of splenic conservation. Arch Surg. 1979;114:449-54.

22. Traub A, Giebink GS, Smith C. Splenic reticuloendothelial function after splenectomy, spleen repair and spleen autotransplantation. N Engl J Méd. 1987;317:1559-64.

23. Times W, Leemans R: Splenic autotransplantation and the immune system. Ann Surg. 1992;215:256-60.

24. Albrecht RM, Schermer CR, Morris A. Nonoperative management of blunt splenic injuries: Factors influencing success in age $>55$ years. Am Surg. 2002;68:227-31.

25. Witztum JL, Steinberg D: As hiperlipoproteinemias. In: Cecil, editor. Tratado de Medicina Interna. 21a Edição. Rio de Janeiro: Guanabara Koogan; 2001, p.1212-24.

26. Mahley RW, Weisgraber KH, Farese RV. Disorders of lipid metabolism. In: Williams, editor. 9th edition. United States: W.B.Saunders Company; 1998, p. 1099-153.

27. Assmann G, Schulte H. Relation of high-density lipoprotein cholesterol and triglycerides to incidence of atherosclerotic coronary artery disease. Am J Cardiol. 1992;70:733-7.

28. Gordon DJ, Rifkind BM. High-density lipoprotein. The clinical implications of recent studies. N Engl J Med. 1989;321:1311-6.

29. Kinosian B, Glick H, Garland G. Cholesterol and coronary heart disease: predicting risks by levels and ratios. Ann Intern Med. 1994;121:641-7. 